\title{
Acetylene Resembling Effect of Ethylene on Seed Germination: Evaluating the Effect of Acetylene Released from Calcium Carbide
}

\author{
Kambiz MASHAYEKHI ${ }^{1}$, Aida SHOMALI ${ }^{1}$, Seyyed Javad MOUSAVIZADEH ${ }^{2 *}$ \\ ${ }^{I}$ University of Agricultural Science and Natural Resources, College of Plant Production, Department of Horticulture, Gorgan, Iran \\ ${ }^{2}$ University of Tehran, Faculty of Agriculture and Natural Resources, Department of Horticultural Sciences, Karaj, Iran; mousavizadeh@ut.acir (*orresponding author)
}

\begin{abstract}
Some vegetable seeds need a very long time to germinate. In these kinds of seeds the second phase of germination is very long. As acetylene's chemical structure is almost similar to the gaseous hormone ethylene, its' physiological effect on seed germination should be very similar as well. Therefore, an experiment was established in order to enhance seed germination, by treating seeds with acetylene released from interaction of calcium carbide $\left(\mathrm{CaC}_{2}\right)$ with water $\left(\mathrm{H}_{2} \mathrm{O}\right)$. A simple system was designed for efficient and proper use of gaseous acetylene resulted from the two substrates interaction, which conducted the produced gas obtained inside the interaction chamber into a sealed container wherein seeds were floating in water. This experiment aimed to evaluate the effect of one concentration of acetylene with different exposure periods (between 1 to 8 hours) on parsley, celery and Swees chard seeds' germination (chosen as late germinating vegetables). The effect of acetylene on seed germination speed and percent was investigated. There were significant differences in both percent and speed of germination within the various treatments. By floating for 3,5 and 3 hours for parsley, celery and Swiss chard respectively, the highest germination rates were observed. The highest germination speed was achieved by 5,5 and 3 hours floating respectively for parsley, celery and Swiss chard. Based on the results obtained, the current experiment suggests that acetylene has positive effect on enhancing seed germination of named vegetables, and played the role of ethylene, its effects resembling in regard to seed germination process.
\end{abstract}

Keywords: acetylene, calcium carbide, ethylene, exposure period, germination

\section{Introduction}

Seed germination is the most important and the first step of vegetable growing. Most of economic loss in vegetable crops is due to delayed and poor germination. Thus, a new method for improving seed germination is a valuable solution for preventing economical loss and obtaining higher yields and income.

Seed germination, alike other processes of plant physiology, is regulated by hormones and plant regulators and one of them, involved in germination, is ethylene $\left(\mathrm{C}_{2} \mathrm{H}_{4}\right)$ (Taiz and Ziger, 2002; Siriwitayawan et al., 2003; Cervantes, 2006; Mantilla and Matilla-Vázquez, 2008; Miransari and Smith, 2014). The effect of ethylene on breaking seed dormancy and initiation of seed germination was studied in many plants, including cereals (Taiz and Zeiger, 2002) and lettuce seeds (Abeles, 1986). On the other hand, the inhibitory effect of light or heat on lettuce seeds was noted and this was due to inhibition of ethylene production by these factors (Abeles et al., 2012). A positive correlation between increasing endogenous ethylene and the speed of germination was reported for peanut (Arachis hypogaea) seeds by Taiz and Zeiger (2002). In addition, Dutt et al. (2004) showed the positive effect of 1-aminocyclopropane-1carboxylic acid (ACC) as an ethylene biosynthetic precursor, in reducing the time needed for seedlings' emergence of Impatiens seeds.

Application of ethylene as a gas is not possible in experimental and non-experimental cases, because its utilization is very difficult due to the gaseous nature. Discovering ethylene releasing compounds such as ethephon (2chloroethylphosphonic acid) in the $1960_{\mathrm{s}}$ was considered to solve in part this problem (Taiz and Ziger, 2002; Abbasi $e t$ al., 2012), but because it is very expensive, it is not economic efficient for vegetable growers to use. On the other hand, the amount of ethylene produced by this substance is not under control, so there is no confidence about the ability of this substance to induce the effects of ethylene in concentration sensitive cases (Zhang et al., 2010).

Exothermic hydrolysis reaction of calcium carbide is known to produce acetylene $\left(\mathrm{C}_{2} \mathrm{H}_{2}\right)$ gas (Patnaik, 2003; Carreiro et al., 2010). Therefore, in this study calcium carbide was used as an accessible and economic compound.

There are several studies that confirmed the positive effect of soil application of calcium carbide on enhancing germination of okra seeds (Kashif et al., 2008), okra yield (Kashif et al., 2012), potato yield (Abbasi et al., 2012) and rice (Akhter et al., 2004). Also, the promoting effect of different concentrations of calcium carbide on tomato seed germination was evaluated by Siddiq et al. (2011); they also mentioned the inhibitory effect of high density of calcium carbide on tomato seed germination. 


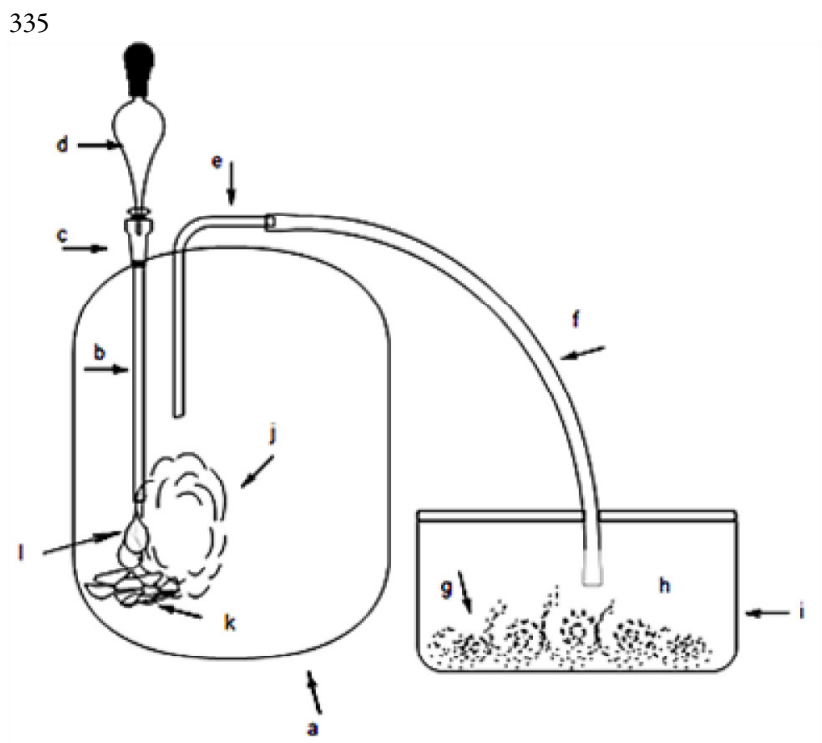

Fig. 1. Schematic picture of the programmed system for producing acetylene solution; Reaction chamber (a); Water pipe (b) which leads to reaction chamber; Stopcock (c); Water dropper (d); Gas pipe (e) which leads to the water chamber; Gas transfer hose (f); Seeds (g); Water (h); Water chamber (i); Acetylene gas (j); Calcium carbide particles (k); Drops of water (l)

Based on Rylski et al. (1974), different exposure periods to ethylene had different effects on potato (Solanum tuberosuim L. cv. 'Russet Burbank') sprouting. Thus, not only the concentration, but also exposure period of ethylene, has strong effect on seed physiology.

As the effectiveness of different concentrations of ethylene shown in previous studies, the current experiment aimed to evaluate the effect of optimum concentration of acetylene resulted from using $\mathrm{CaC}_{2}$, with different exposure periods, as an inexpensive and accessible source of acetylene; introducing a system for proper usage of calcium carbide in experimental or non-experimental cases was also studied.

\section{Materials and Methods}

\section{System designing}

A system was designed to facilitate the application of gaseous acetylene on seeds. As shown in Fig. 1, within the designed system, water drops from water dropper on calcium carbide solid particles which are placed inside the interaction chamber. Interaction starts once the water drops reach on calcium carbide particles; thus, gaseous acetylene is released and conducted into the water chamber by gas transfer hose. Seeds are found in the water chamber, and thus exposed to acetylene.

In this study $80 \mathrm{~g}$ of calcium carbide and about $44 \mathrm{~g}$ distilled water (1:2 molar ratio of calcium carbide and water) were used, according to equation:

$$
\mathrm{CaC}_{2}(\mathrm{~s})+2 \mathrm{H} 2 \mathrm{O}_{(\mathrm{l})} \Rightarrow \mathrm{C} 2 \mathrm{H} 2_{(\mathrm{g})}+\mathrm{CaOH}_{2}(\mathrm{aq})
$$
(Carreiro et al., 2010).

Seeds floated in a sealed container within the system, containing acetylene solution, for different periods of time, from 1 to 8 hours.

\section{Germination experiment}

Seeds of parsley (Petroselinum crispum), celery (Apium graveolens) and Swiss chard (Beta vulgaris) were used. The seeds, plants respectively, were selected as late germinating vegetables. After seed treatment with acetylene, they were transferred in Petri dishes covered with filter paper and placed at $25^{\circ} \mathrm{C}$.

Germination tests were done using three replications, each replication containing 30 seeds and arranged as complete randomized block design (CRD). The stage of visible radicle emergence was considered as a symptom of germination for parsley and celery seeds and first exited radicle for Poly germ Swiss chard seeds. Germinated seeds were counted daily and discarded. Seed germination speed was calculated according to formula cited by Mavi et al. (2010):

$$
M G T=\frac{\sum(n T)}{\sum n}
$$

$\mathrm{n}=$ number of seeds germinated at time $\mathrm{T}$ at $25^{\circ} \mathrm{C}$;

$\mathrm{T}=$ time pasted from the beginning of the germination test;

$$
\sum \mathrm{n}=\text { total germination. }
$$

\section{Imbibition curve}

After the analysis of results, imbibition period was measured for the highest significant treatments and control. At first, dry weight of a hundred seed of each vegetable was measured, then wet weight of imbibed seeds was recorded until radicle emergence and before green leaf were observed respectively, then the imbibition curve was drown.

\section{Results}

This study has shown the reasonable relation between different floating periods in acetylene solution on seed germination speed and percent (Table 1). There were significant differences in both germination speed and percent among the different treatments, and also highly significant differences between treatments and control $(\mathrm{p}<$ $0.05)$, as shown in Table 2.

The highest germination percent was achieved by 2, 4 and 2 hours floating respectively for parsley, celery and Swiss chard, and the highest germination speed was noted in the case of 4, 4 and 2 hours floating interval respectively for parsley, celery and Swiss chard (Table 1). In addition, as the exposure period increased, both percent and speed of germination increased in comparison with control (no exposure) and the inhibitory effect of treatment took place in longer exposure periods.

Comparing the imbibition curve of the highest significant seed treatments with control it indicated that the second phase of germination was shorter for treated seeds. That caused the increase in germination speed. As shown in Figs. 2, 3 and 4 the second phase of seed germination for the highest significant treatments among each of parsley, celery and chard seeds, was shorter than control, therefore they had faster water imbibition. Thus, radicle emerge faster in the highest significant treatments; this was noted respectively after about 160,70 and 260 hours, while radicle emergence in control seeds for parsley, Swiss chard and celery was observed after 260,142 and more than 380 hours. 
Table 1. Seed germination percent and speed

\begin{tabular}{|c|c|c|c|c|c|c|}
\hline \multirow[b]{2}{*}{$\begin{array}{l}\text { Treatment } \\
\text { Period (h) }\end{array}$} & \multirow[b]{2}{*}{$\begin{array}{l}\text { Germination } \\
\text { percent }\end{array}$} & \multicolumn{2}{|l|}{ Parsley } & \multirow{2}{*}{$\begin{array}{c}\text { Celery } \\
\text { Germination speed }\end{array}$} & \multicolumn{2}{|c|}{ Swiss chard } \\
\hline & & Germination speed & $\begin{array}{l}\text { Germination } \\
\text { percent }\end{array}$ & & Germination percent & Germination speed \\
\hline 0 & $80^{\mathrm{abc}}$ & $0.00612^{\mathrm{dc}}$ & $30^{\mathrm{d}}$ & $0.0027^{\mathrm{cd}}$ & $30^{c}$ & $0.0075^{c}$ \\
\hline 1 & $81.1^{\mathrm{ab}}$ & $0.00706^{\mathrm{b}}$ & $64.4^{\mathrm{bc}}$ & $0.0032^{b c}$ & $54.4^{\mathrm{b}}$ & $0.017^{\mathrm{b}}$ \\
\hline 2 & $86.66^{\mathrm{aa}}$ & $0.00734^{\mathrm{b}}$ & $44.4^{\mathrm{dc}}$ & $0.0033^{\mathrm{ab}}$ & $80^{\mathrm{a}}$ & $0.036^{\mathrm{a}}$ \\
\hline 3 & $83.3^{\mathrm{ab}}$ & $0.00712^{\mathrm{b}}$ & $82.2^{\mathrm{ab}}$ & $0.0036^{\mathrm{ab}}$ & $45.5^{\mathrm{bc}}$ & $0.011^{\mathrm{bc}}$ \\
\hline 4 & $85.5^{\mathrm{ab}}$ & $0.00863^{\mathrm{a}}$ & $91.1^{\mathrm{aa}}$ & $0.0037^{\mathrm{aa}}$ & $51.1^{\mathrm{b}}$ & $0.018^{b}$ \\
\hline 5 & $74.4^{\mathrm{bc}}$ & $0.00686^{\mathrm{b}}$ & $32.23^{d}$ & $0.0023^{\mathrm{d}}$ & $37.7^{\mathrm{c}}$ & $0.095 c$ \\
\hline 6 & $71.3^{\mathrm{cd}}$ & $0.00620^{c}$ & $40^{\mathrm{dc}}$ & $0.0023^{\mathrm{dc}}$ & $38.8^{\mathrm{bc}}$ & $0.010^{\mathrm{bc}}$ \\
\hline 7 & $73.3^{\mathrm{cd}}$ & $0.00552^{\mathrm{d}}$ & & & $45.5^{\mathrm{bc}}$ & $0.011^{\mathrm{bc}}$ \\
\hline 8 & $63.3^{d}$ & $0.00571^{\mathrm{dc}}$ & & & $37.7^{\mathrm{bc}}$ & $0.010^{\mathrm{bc}}$ \\
\hline
\end{tabular}

Different letters denote significant differences among rate and percent of germination

Means followed by the same letter are not significantly different at $5 \%$ by LSD

Table 2. Analysis of variance for speed and percent of germination

\begin{tabular}{lccc}
\hline SV & & Germination percent & Germination speed \\
\hline Celery & df & & Ms \\
Treat & 6 & $1806.70741^{* *}$ & $0.00000104^{*}$ \\
Error & 14 & $209.25958^{* *}$ & $0.00000033^{*}$ \\
$\begin{array}{l}\text { Parsley } \\
\text { Treat }\end{array}$ & 8 & $176.228560^{*}$ & $0.00000279^{* *}$ \\
Error & 18 & $54.712099^{*}$ & $0.00000015^{*}$ \\
Swees chard & & & \\
Treat & 8 & $633.744856^{* *}$ & $0.00022693^{* *}$ \\
Error & 18 & $95.473251^{* *}$ & $0.00002922^{* *}$ \\
\hline $\begin{array}{l}\text { significant at the } 0.05 \text { probability level } \\
\text { significant at the } 0.01 \text { probability level }\end{array}$
\end{tabular}

significant at the 0.01 probability level

chard imbibition

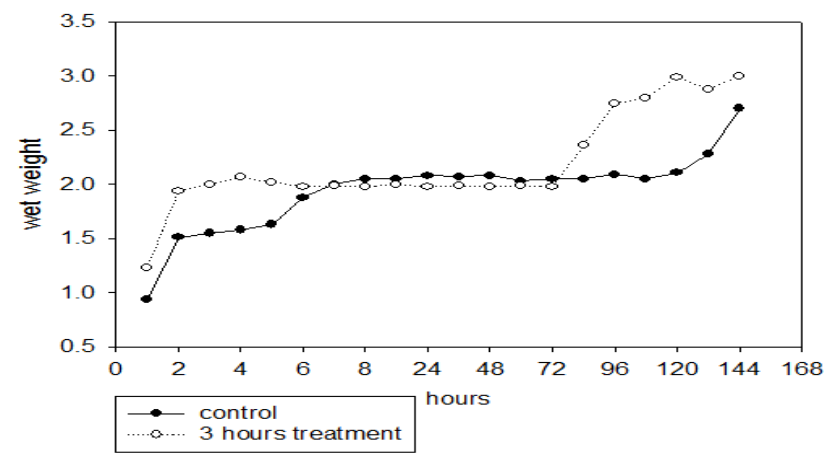

Fig.3. Imbibition curve of control and the highest significant treatment of chard seeds

\section{Discussions}

This study supports pervious findings about the stimulatory effect of calcium carbide on germination enhancement of different genotypes of tomato and okra (Siddiq et al., 2011; Kashif et al., 2012).

It can be concluded from the data obtained that acetylene enhanced germination speed by shortening the second phase of imbibitions, similar to the effects produced by ethylene. This enhancement can be referred to as mimicking the effect of ethylene on increasing cell expansion in radicle and also increasing water absorption in response to increasing water potential in the embryonic axis (Matilla and Matilla-Vázquez, 2008).

The best floating time was equal to the adequate time

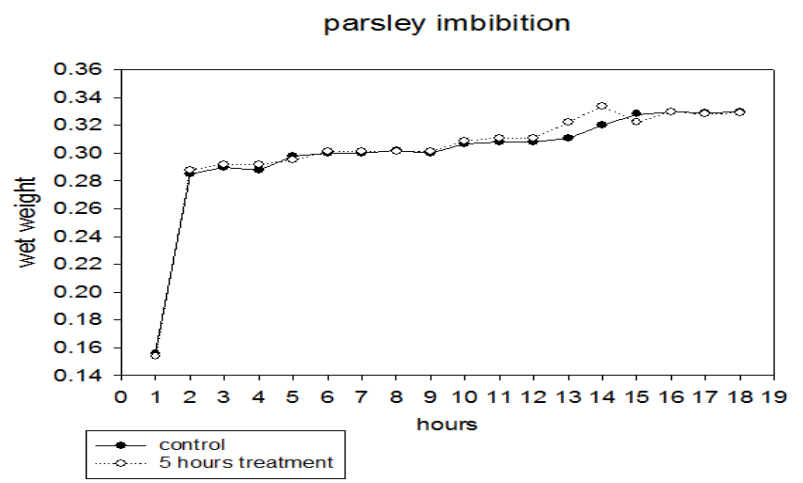

Fig. 2. Imbibition curve of control and the highest significant treatment of parsley seeds

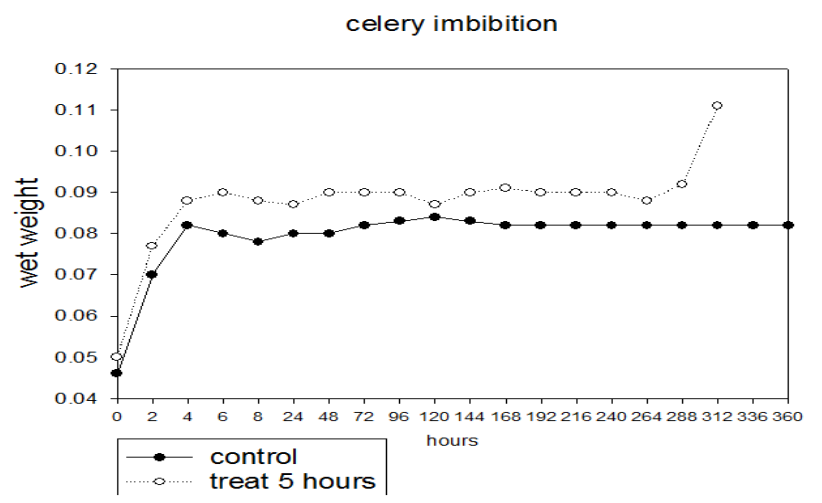

Fig. 4. Imbibition curve of control and the highest significant treatment of celery seeds

needed to start the second phase of seed germination. Therefore, it can be concluded that the physiological effect of acetylene started at the beginning of the second phase of seed imbibition, while the inhibitory effect of continues exposure period may take place slowly, as same as the inhibitory effect of long ethylene exposure (Rylski et al., 1974) seen on 'White Rose' potatoes sprout elongation and respiration.

In addition, the effect of acetylene can be referred to as also similar to the role of ethylene in synergist crosstalk with gibberellins (GA) - a hormone known as germination, growth and flowering promoter (Weiss and Ori, 2007); GA is also a factor that affects several process in germination such as mobilization of endosperm reverse, dormancy breakage of embryo and weakening of the embryo's endosperm (Taiz and Ziger, 2003), therefore acetylene may also influence these processes. 
337

On the other hand, previous studies showed that ethylene may play its role in promoting seed germination by itself, as researchers indicated that ethylene synthesis in vigorous seeds was more abundant than its production in low vigor seeds (Siriwitayawan et al., 2003; Mantilla and Matilla-Vázquez, 2008) and also production of ethylene in low vigor seed happens later and lesser in contrast to its accumulation in vigorous seeds (Dutt et al., 2004). Siriwitayawan et al. (2003) also proofed that reduced vigor of seeds may be a result of the reduced capacity of seeds to produce ethylene.

Another role of ethylene related to promoting germination is suppressing abscisic acid (ABA) by affecting its metabolism or signaling pathway, which was noticed by Corbineau et al. (2014), by using inhibitors of ethylene biosynthesis or its action.

\section{Conclusions}

The direct or indirect role of ethylene in seed physiology is still a complex mechanism that remains to be studied, but what was obvious in the current study was the role of acetylene over enhancing seed germination. It can be concluded based on the results obtained that acetylene released from calcium carbide mimics the role of ethylene in seed germination. The hereby study suggested that calcium carbide may be used as an economic and accessible material for improving germination, thus to be introduced within a possible system for efficient utilizing of calcium carbide in experimental and application cases, for acetylene release.

\section{References}

Abbasi NA, Zahoor M, Khan HA, Qureshi AA (2012). Effect of encapsulated calcium carbide application at different growth stage on potato (Solanum tubersum L.) growth, yield and tuber quality. Pakistan Journal of Botany 44(5):1543-1550.

Abeles FB (1986). Role of ethylene in Lactuca sativa CV 'Grand Rapids' Seed Germination. Plant Physiology 81(3):780-787.

Abeles FB, Morgan PW, Saltveit Jr ME (2012). Ethylene in plant biology, 2nd Edition. Academic Press, California.

Akhter A, Arshad MJ, Khalid M, Yaseen AM (2004). Effect of calcium carbide-derived ethylene on growth and yield of rice. Pakistan Journal of Life and Social Sciences 2(1):85-88.

Cervantes E (2006). Ethylene in seed germination and early root development. Floriculture, Ornamental and Plant Biotechnology 1:429-438.

Corbineau F, Xia Q, Bailly C, El-Maarouf-Bouteau H (2014). Ethylene, a key factor in the regulation of seed dormancy. Frontiers in Plant Science 5 doi: 10.3389/fpls.2014.00539

Dutt M, Kester S, Geneve R (2004). Elevated levels of ethylene during germination reduces the time to emergence in impatiens. Acta Horticulturae 631:43-47.

Kashif S, Yaseen M, Arshad M, Ayub M (2008). Response of okra (Hibiscus esculentus L.) to soil given encapsulated calcium carbide. Pakistan Journal of Botany 40(1):175-181.

Kashif SUR, Yaseen M, Raza H, Kirn A (2012). Improving seed germination and green pod yield in okra (Hibiscus esculentus L.) using calcium carbide-a new source of ethylene. Journal of Plant Nutrition 35(13):2024-2036.

Carreiro LG, Burke AA, Dubois L (2010). Co-generation of acetylene and hydrogen for a carbide-based fuel system. Fuel Processing Technology 91(9):1028-1032.

Matilla AJ, Matilla-Vázquez MA (2008). Involvement of ethylene in seed physiology. Plant Science 175(1):87-97.

Mavi K, Demir I, Matthews S (2010). Mean germination time estimates the relative emergence of seed lots of three cucurbit crops under stress conditions. Seed Science and Technology 38(1):14-25.

Patnaik P (2003). Handbook of inorganic chemicals (Vol 28). New York, McGraw-Hill.

Miransari M, Smith DL (2014). Plant hormones and seed germination. Environmental and Experimental Botany 99:110121.

Rylski I, Rappaprot L, Pratt HKD (1974). Dual effects of ethylene on potato dormancy and sprout growth. Plant Physiology 53:658662.

Siddiq S, Ahmed W, Yaseen M, Ali Q, Arshad M (2011). Effect of calcium carbid on seed germination of tomato genotypes under controlled condition. International Journal for Agro Veterinary and Medical Sciences 5:336-348.

Siriwitayawan G, Dutt M, Kester S, Downie B, Geneve R, Nicolás G, Pritchard HW (2003). Ageing in tomato reduces the capacity of seeds to produce ethylene, while priming increases ethylene evolution during germination. In: The biology of seeds: recent research advances. Proceedings of the Seventh International Workshop on Seeds, Salamanca, Spain, 2002, CABI Publishing pp 441-446.

Taiz L, Zeiger E (2002). Plant physiology. Sinauer Associates.

Weiss D, Ori N (2007). Mechanisms of cross talk between gibberellin and other hormones. Plant Physiology 144(3):1240-1246.

Zhang W, Hu W, Wen CK (2010). Ethylene preparation and its application to physiological experiments. Plant Signaling and Behavior 5(4):453-457. 